\title{
Effects of in vitro antibiotic resistance on treatment: Bismuth-containing regimens
}

\author{
Naoki Chiba MD FRCPC
}

N Chiba. Effects of in vitro antibiotic resistance on treatment: bismuth-containing regimens. Can J Gastroenterol 2000;14(10): 885-889. Bismuth compounds remain useful for Helicobacter pylori eradication therapy. These include colloidal bismuth subcitrate (CBS), bismuth subsalicylate (BSS) and, most recently, ranitidine bismuth citrate (RBC). CBS appears to prevent the development of imidazole resistance when coadministered with nitroimidazoles. Traditional triple therapy with bismuth, metronidazole and tetracycline or amoxicillin (BMT/A) only partially overcomes metronidazole resistance. However, the addition of a PPI to bismuth triple therapy largely overcomes established metronidazole resistance if treatment is given for at least one week or more. When RBC rather than PPI is used with clarithromycin, this dual regimen appears to be more effective in preventing the development of secondary clarithromycin resistance. The triple combination of RBC, metronidazole and clarithromycin appears to be effective against metronidazole resistant strains of $\mathrm{H}$ pylori. Thus, overall, there is some evidence that bismuth compounds may prevent the development of antibiotic resistance and that existing antibiotic resistance may at least be partially overcome in vitro and in vivo. With the growing emergence of $\mathrm{H}$ pylori resistance to metronidazole and clarithromycin, further research to clarify the role of bismuth compounds is required.

Key Words: Antimicrobial susceptibility; Bismuth; Clarithromycin; Eradication; Helicobacter pylori; Metronidazole

\section{Effets de la résistance aux antibiotiques in vitro sur le traitement : Schémas à base de bismuth}

RÉSUMÉ : Les composés à base de bismuth restent utiles pour le traitement d'éradication d'Helicobacter pylori. On y retrouve le subcitrate de bismuth colloïdal (SBC), le subsalicylate de bismuth (SSB), et plus récemment, le citrate de bismuth-ranitidine (CBR). Le SBC semple apte à prévenir le développement de la résistance à l'imidazole lorsqu'on l'administre avec des nitro-imidazoles. La trithérapie habituelle à base de bismuth, métronidazole et tétracycline ou amoxicilline (BMT/A), ne vient que partiellement à bout de la résistance au métronidazole. Par contre, l'ajout d'un IPP à la trithérapie à base de bismuth abolit pour une bonne part la résistance au métronidazole avérée si le traitement dure au moins une semaine. Lorsqu'on utilise le CBR plutôt qu'un IPP avec la clarithromycine, ce double traitement semble plus efficace à prévenir le développement de la résistance secondaire à la clarithromycine. La trithérapie à base de CBR, métronidazole et clarithromycine semble efficace contre les souches d'H. pylori résistantes au métronidazole. Donc, dans l'ensemble, les composés de bismuth peuvent prévenir le développement d'une résistance aux antibiotiques et la résistance aux antibiotiques déjà établie peut être au moins partiellement vaincue in vitro et in vivo. Compte tenu de la résistance croissante de $H$. pylori au métronidazole et à la clarithromycine, il faudra approfondir la recherche pour clarifier le rôle des composés de bismuth.
$\mathrm{T}$ he discovery of Helicobacter pylori (1) has revolutionized the ability to cure the approximately $15 \%$ of infected people who develop peptic ulcer disease and the rare patient with mucosa-associated lymphoid tissue lymphoma caused by this infection (2). Although causal associations between this infection and gastric carcinoma (3) have been identified, it still remains to be seen whether early eradication of this infection can prevent subsequent development of cancer.

While the importance of $H$ pylori is well established, the ideal treatment regimen(s) remains somewhat elusive. The key antimicrobial agents, bismuth, amoxicillin, nitroimidazoles and clarithromycin, are commonly used in combination therapy. The gold standard triple therapies are one-

Surrey GI Clinic/Research, Guelph, and McMaster University, Hamilton, Ontario

Correspondence: Dr Naoki Chiba, Surrey GI Clinic/Research, 105-21 Surrey Street West, Guelph, Ontario N1H 3R3. Telephone 519-836-1341, fax 519-836-8210, e-mail chiban@on.aibn.com

Received for publication May 9, 2000. Accepted June 13, 2000 
TABLE 1

Eradication of metronidazole-sensitive (MS) and -resistant (MR) strains of Helicobacter pylori

\begin{tabular}{lccc}
\hline & \multicolumn{2}{c}{ Eradication (\%) } \\
Author (reference) & Drugs & MS & MR \\
\hline Chiba and Hunt (17) & BMT & $89(\mathrm{n}=350)$ & $50.6(81 / 160)$ \\
$\begin{array}{l}\text { Penston and McColl } \\
\quad \text { BMT/A }\end{array}$ & $86(\mathrm{n}=787)$ & $58(\mathrm{n}=322)$ \\
Tytgat (19) & & & \\
& BMT & $85-98$ & $32-87$ \\
& BMA & $91-97$ & $19-68$ \\
\hline
\end{tabular}

A Amoxicillin; BMT Bismuth plus metronidazole plus tetracycline

week, twice daily treatment with proton pump inhibitors (PPIs) plus clarithromycin and amoxicillin or a nitroimidazole (metronidazole or tinidazole), as recommended by numerous worldwide consensus conferences (4-7). Major factors affecting treatment success are lack of compliance due to either drug-induced side effects or the many pills consumed, and antibiotic resistance. The development of $H$ pylori resistance to nitroimidazoles and clarithromycin is emerging as an important factor that adversely affects treatment success.

The available literature of the effects of in vitro antibiotic resistance on treatment are reviewed, with particular focus on bismuth-containing regimens. Surprisingly few data were identified in the literature to address this topic.

\section{RATIONALE FOR BISMUTH COMPOUNDS IN THE TREATMENT OF H PYLORI}

Bismuth compounds have been used for centuries to treat gastrointestinal disorders such as dyspeptic symptoms and diarrheal disorders (8). In particular, compounds such as colloidal bismuth subcitrate (CBS) have been used to heal duodenal ulcers $(9,10)$. Bismuth compounds are topically active and have bactericidal effects against $H$ pylori, possibly by disrupting its adhesion to epithelial cells or by inhibiting enzymes secreted by $H$ pylori, such as proteases, lipases, glycosidases and phospholipases (11), ultimately leading to structural degeneration of $H$ pylori.

Less than $1 \%$ of the oral dose of commonly used bismuth compounds such as CBS, bismuth subsalicylate (BSS) and ranitidine bismuth citrate (RBC) is absorbed (8). Although bismuth neurotoxicity is a potential concern, this occurs only when doses far in excess of those used for $\mathrm{H}$ pylori eradication are used (8).

\section{BISMUTH MAY PARTLY PREVENT NITROIMIDAZOLE RESISTANCE}

Early on, it was observed that when nitroimidazoles such as tinidazole were given alone, $\mathrm{H}$ pylori resistance developed readily. In one study, the coadministration of CBS with tinidazole reduced the development of $H$ pylori resistance to tinidazole from $70 \%$ to $10 \%$ (12).

In another study, when tinidazole was given with CBS, resistance to tinidazole developed in 40\%; when tinidazole was given with amoxicillin, resistance developed in 35\% (13). It was only when the three drugs were used together for 10 days that the rate of development of imidazole resistance dropped to only $3 \%$ (13). Thus, combinations of various antimicrobials appear to be important in preventing nitroimidazole resistance.

In treating patients with established nitroimidazole resistance, can the addition of a bismuth compound eradicate even resistant organisms? Two studies using dual therapy have reported such data. In the first study, CBS was used with tinidazole for 10 days and eradicated $91 \%$ of metronidazole-sensitive strains, while only $20 \%$ of resistant strains were eradicated (12). In the other study, BSS was used with metronidazole for 10 days, eradicating $82 \%$ of metronidazole-sensitive and $17 \%$ of metronidazole-resistant strains (14). The eradication rate in the metronidazole-resistant strains was no better than if bismuth compounds were given alone (15). Thus, the simple addition of a bismuth compound to a nitroimidazole does not overcome established imidazole resistance.

The first recommended gold standard, triple therapy was bismuth, metronidazole and tetracycline or amoxicillin $(15,16)$. The effectiveness of these triple therapies for eradicating metronidazole-sensitive and -resistant strains of H pylori has been summarized in several reviews (17-19) (Table 1). While the efficacy is much reduced in resistant strains, the $50 \%$ or greater success is better than that of dual therapy.

The addition of a PPI to traditional bismuth triple therapy improves eradication efficacy (20). In a one-week, randomized, controlled trial comparing omeprazole, bismuth, metronidazole and tetracycline (OBMT) with bismuth, metronidazole and tetracycline (BMT), the eradication rate was $98 \%$ with OBMT and $83 \%$ with BMT ( $\mathrm{P}=0.02)$ (21). Only five of the 100 strains had baseline metronidazole resistance. Of these strains, all three were eradicated with OBMT, but none of two were eradicated with BMT.

Both omeprazole and lansoprazole have been studied with BMT. Much of the available data for PPI-BMT in metronidazole-sensitive and -resistant strains have come from de Boer (21-28) in the Netherlands, who pretreated patients for three days with a PPI, then co-administered BMT for various durations. He has studied BMT for one to seven days (21-28). The one-day study used eight times daily dosing (22), while for two to seven days, the drugs were given four times daily. While the data are sparse, Figure 1, incorporating data from these studies, shows that the longer the duration of bismuth triple therapy with the PPI, the greater the improvement in efficacy in metronidazole-resistant strains, such that by one week, eradication efficacy appears unaffected by metronidazole resistance. In the one American study of lansoprazole with BMT, eradication in metronidazole-sensitive strains was $90 \%$ ( 26 of 29), while in resistant strains, the efficacy was reduced to $41 \%$ (seven of 17) (29). However, in this study, the drugs were given only twice daily compared with the more conventional four times daily, which may explain the reduced efficacy. 
Overall, the PPI-BMT regimen for one week has been recommended as an alternative treatment after initial treatment failures and when $\mathrm{H}$ pylori metronidazole resistance is either known or suspected.

\section{RBC MAY PREVENT THE EMERGENCE OF RESISTANCE}

$\mathrm{RBC}$ is a unique, soluble salt that combines the gastric antisecretory activity of ranitidine with the mucosal protective, antipepsin and anti-H pylori properties of bismuth $(30,31)$. It is not simply an admixture of bismuth citrate with ranitidine.

One study specifically addressed whether the emergence of resistance to $H$ pylori could be reduced when antibiotics were coadministered with RBC (32). Organisms were subcultured on media with $\mathrm{RBC}$ or no drug, and the rate of emergence of spontaneous resistance of $H$ pylori to antibiotics was determined. When subcultured with RBC, the emergence of metronidazole resistance was significantly reduced, even in the one strain particularly prone to metronidazole resistance. The emergence of resistance to clarithromycin was reduced in one of two H pylori strains tested (32). An interesting observation was that $H$ pylori was surrounded by bismuth oxychloride, with a greater number of bismuth molecules around the strain that showed a larger reduction in resistance. It was hypothesized that the coating of $\mathrm{H}$ pylori with bismuth molecules led to greater $H$ pylori killing when metronidazole was added.

\section{RBC DUAL THERAPY IN VITRO MAY BE EFFECTIVE AGAINST CLARITHROMYCIN-RESISTANT STRAINS}

In vitro (33-35) and in mouse models (34), the combination of RBC with clarithromycin results in synergistic increases in the activity against $H$ pylori, even in those resistant to clarithromycin $(33,35)$. Using a two-dimensional checkerboard array, Osato et al (36) assessed the interaction of RBC and clarithromycin. In 10 of $11 \mathrm{H}$ pylori isolates, the clarithromycin minimum inhibitory concentration $(\mathrm{MIC})_{90}$ was reduced an average of ninefold when combined with $\mathrm{RBC}$ to still achieve microbial killing, and one clarithromycin-resistant isolate $\left(\mathrm{MIC}_{90}\right.$ greater than $256 \mu \mathrm{g} / \mathrm{mL}$ ) became sensitive to clarithromycin when combined with RBC. In a separate report using the same methodology, eight of 10 clarithromycin-resistant isolates became susceptible to clarithromycin (35).

RBC combined with metronidazole in vitro also demonstrated either total or partial synergy against metronidazoleresistant strains, as determined by a fractional inhibitory index of 0.5 or less (37). Dual therapy with RBC and clarithromycin may be effective against metronidazole-resistant $H$ pylori strains, with eradication reported in 11 of 11 strains (38).

\section{IN VIVO DATA}

Whether RBC added to clarithromycin is effective in treating clarithromycin-resistant $H$ pylori strains in vivo remains unclear, with opposing study results published.

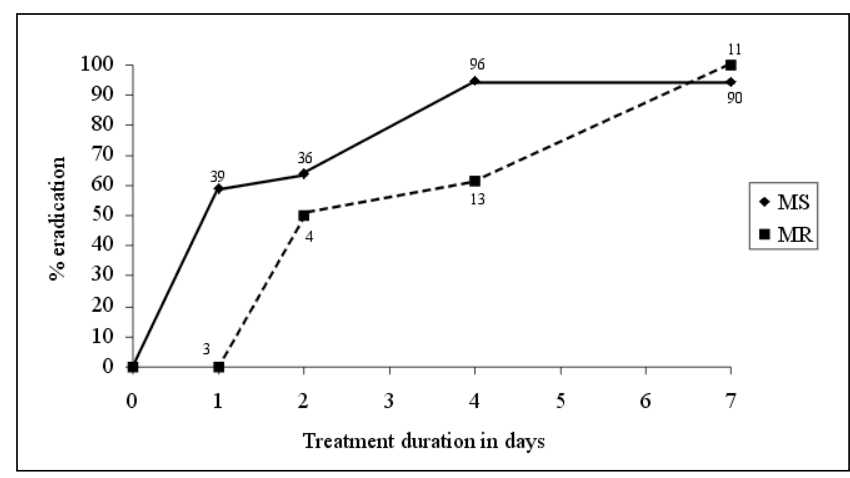

Figure 1) Proton pump inhibitor plus bismuth, metronidazole and tetracycline triple therapy: de Boer eradication rates versus treatment duration. The numbers adjacent to the points are the number of strains evaluated. MR Metronidazole resistant; MS Metronidazole sensitive. Data from references 21-28

In an American duodenal ulcer study, patients infected with $H$ pylori were treated with RBC plus clarithromycin dual therapy (39). The RBC combination did not overcome clarithromycin resistance (defined by MIC greater than $4 \mu \mathrm{g} / \mathrm{mL}$ ), with an eradication rate of only $8 \%$ (three of 38) in resistant strains; in those with susceptible and intermediate strains, the eradication rate was $82 \%$ (208 of 254). The higher dose of clarithromycin $1.5 \mathrm{~g} /$ day was not more effective than the standard $1 \mathrm{~g}$ daily dose.

Mégraud et al (40) reported from an international study that a 14-day treatment with RBC plus clarithromycin dual therapy overcame clarithromycin resistance in 11 of 12 (92\%) H pylori strains, while an omeprazole and clarithromycin regimen was less effective (three of eight [38\%] eradicated) (40). Thus, with these opposing results, the role of dual therapy in eradicating clarithromycin-resistant $\mathrm{H}$ pylori remains to be clarified.

\section{IN VIVO EMERGENCE OF ANTIBIOTIC RESISTANCE}

Acquired clarithromycin resistance by $\mathrm{H}$ pylori after treatment with RBC and clarithromycin appeared to be reduced in two in vivo studies. In the Mégraud study reported above (40), one of 39 patients (3\%) treated with RBC and eight of $44(18 \%)$ of those treated with omeprazole acquired resistance to clarithromycin after treatment failure $(\mathrm{P}=0.046)$. Similarly, Osato et al (41), in a study of 466 patients with clarithromycin-susceptible $H$ pylori, reported that, of those with treatment failure, $8 \%$ of those treated with RBC and clarithromycin and $17 \%$ of those treated with omeprazole and clarithromycin developed clarithromycin resistance $(\mathrm{P}<0.01)$. These data suggest that $\mathrm{RBC}$ cotherapy may reduce the emergence of antibiotic resistance.

\section{IN VIVO RBC TRIPLE THERAPIES}

$\mathrm{RBC}$, tetracycline and clarithromycin triple therapy: Graham et al (42) used RBC $400 \mathrm{mg}$ bid, tetracycline $500 \mathrm{mg}$ bid and clarithromycin $500 \mathrm{mg}$ bid for 14 days in an open study of 63 patients with clarithromycin-susceptible $H$ pylori at 
baseline and reported a $94 \%$ eradication success. Of the treatment failures, two of three became resistant to clarithromycin. While the sample size is small, it is unclear why there appeared to be such a large proportion of strains that became resistant compared with the $3 \%$ to $8 \%$ that became resistant compared with RBC-clarithromycin dual therapy $(40,41)$.

$\mathrm{RBC}$, metronidazole and tetracycline triple therapy: Triple therapy with RBC, metronidazole and tetracycline is a combination regimen similar to the traditional bismuth triple therapy. In one study, baseline metronidazole resistance significantly $(\mathrm{P}=0.026)$ reduced eradication efficacy from $97 \%$ in patients with a metronidazole-sensitive strain of $\mathrm{H}$ pylori compared with $57 \%$ in those with a resistant strain (43). These data are similar to those of traditional bismuth triple therapy, as discussed above, with reduced efficacy in resistant strains (Table 1). A Chinese study directly compared $\mathrm{RBC}$ or CBS with metronidazole and tetracycline triple therapy (RBC plus metronidazole plus tetracycline compared with BMT) and reported contrasting results, with 25 of $25(100 \%)$ metronidazole-resistant strains eradicated with the RBC-MT regimen compared with 12 of 16 (75\%, $\mathrm{P}=0.018$ ) eradicated with traditional BMT triple therapy (44). Reasons for the contrasting results between these studies are unknown, and the true effect of metronidazole resistance on treatment efficacy remains to be elucidated. However, it is probable that there is a deleterious effect of resistance on efficacy because overall reported results with this regimen are more variable, ranging from $60 \%$ (45) to $92 \%$ (44).

RBC, metronidazole and clarithromycin triple therapy: PPI triple therapy, when combined with clarithromycin and metronidazole, is less effective when $H$ pylori resistance to metronidazole is present (46). Triple therapy with RBC, clarithromycin and metronidazole overcame metronidazole resistance in nine of 10 strains in each of two studies $(38,47)$.

Another clinical trial evaluated the effects of two different RBC triple therapies on resistant strains (48). With metronidazole resistance defined as an MIC greater than $8 \mu \mathrm{g} / \mathrm{mL}$ by the E-test, and clarithromycin resistance as an MIC greater than $2 \mu \mathrm{g} / \mathrm{mL}$, the 20 patients with a metronidazole-resistant strain of $H$ pylori treated for one week with RBC $400 \mathrm{mg}$ bid, metronidazole $500 \mathrm{mg}$ bid and clarithromycin $500 \mathrm{mg}$ bid had $95 \% \mathrm{H}$ pylori eradication. H pylori was also eradicated in three patients with baseline clarithromycin-resistant strains and in the one patient infected with a strain resistant to both antibiotics. In the patients who received amoxicillin $1 \mathrm{~g}$ bid in place of clarithromycin, eradication was $87 \%$ in metronidazole-susceptible strains but only $22 \%$ in metronidazole-resistant strains, suggesting that $\mathrm{RBC}$ triple therapy containing clarithromycin is more effective than amoxicillin in eradicating metronidazole-resistant H pylori.

\section{SUMMARY}

Bismuth compounds most commonly used in H pylori eradication include CBS, BSS and the newer RBC. With the recent focus on antibiotic resistance, the newer $\mathrm{RBC}$ has more resistance data available. Overall, however, there are surprisingly few published data on this important topic.

CBS appears to prevent the development of imidazole resistance when coadministered with nitroimidazoles (12). If amoxicillin is added to the dual therapy, metronidazole resistance may be reduced further (13).

If imidazole resistance is present at baseline, neither the bismuth and imidazole dual therapy $(12,14)$ nor the bismuth, metronidazole and tetracycline or amoxicillin (BMT/A) triple therapy (Table 1) effectively overcomes metronidazole resistance. However, the BMT/A triple therapy partially overcomes metronidazole resistance, with better results than with dual therapy. The newer RBC has been studied in an analogous regimen, and because results are discrepant $(43,44)$, the efficacy of the RBC with metronidazole and tetracycline triple regimen remains unclear.

The addition of a PPI to traditional bismuth therapy (PPI-BMT) helps to overcome established metronidazole resistance; this effect is dependent on the duration of treatment (Figure 1).

In vitro, $\mathrm{RBC}$ combined with metronidazole may prevent the emergence of metronidazole resistance, and RBC combined with clarithromycin may also prevent the emergence of clarithromycin resistance (32). Also in vitro, these dual therapies may be effective against metronidazole- (37) and clarithromycin-resistant $(33,35) \mathrm{H}$ pylori strains. However, in vivo, conflicting study results of the efficacy of RBC with clarithromycin in eradicating clarithromycin-resistant strains have been reported $(39,40)$. A regimen comprising $\mathrm{RBC}$ and clarithromycin appears to be more effective than a regimen comprising a PPI with clarithromycin in preventing clarithromycin resistance in treatment failure $(40,41)$.

The triple combination of RBC, metronidazole and clarithromycin appears to be effective against metronidazole-resistant strains of $H$ pylori, with consistent results reported in three studies $(38,47,48)$.

Overall, there is some evidence that bismuth compounds may prevent the development of antibiotic resistance and that existing antibiotic resistance may at least be partially overcome in vitro and in vivo. Further data on this important topic are hopefully forthcoming.

\section{REFERENCES}

1. Warren JR, Marshall BJ. Unidentified curved bacillus on gastric epithelium in active chronic gastritis. Lancet 1983;i:1273-5.

2. Walsh JH, Peterson WL. The treatment of Helicobacter pylori infection in the management of peptic ulcer disease. N Engl J Med 1995;333:984-91.

3. IARC Monographs on the Evaluation of Carcinogenic Risks to Humans, vol 61. Schistosomes, Liver Flukes and Helicobacter pylori. Lyon: IARC, 1994.

4. Hunt RH, Fallone CA, Thomson AB. Canadian Helicobacter pylori Consensus Conference update: Infections in adults. Can J Gastroenterol 1999;13:213-7.

5. Malfertheiner P, on behalf of The European Helicobacter pylori Study Group (EHPSG). Current European concepts in the management of Helicobacter pylori infection. The Mäastricht Consensus report. Gut 1997;41:8-13.

6. Peura DA. The Report of the Digestive Health Initiative ${ }^{S M}$ International Update Conference on Helicobacter pylori. Gastroenterology 1997;113(6 Suppl):S4-8.

7. Lam SK, Talley NJ. Report of the 1997 Asia Pacific Consensus 
Conference on the management of Helicobacter pylori infection. J Gastroenterol Hepatol 1998;13:1-12.

8. Tillman LA, Drake FM, Dixon JS, Wood JR. Review article: safety of bismuth in the treatment of gastrointestinal diseases. Aliment Pharmacol Ther 1996;10:459-67.

9. Tytgat GNJ. Colloidal bismuth subcitrate in peptic ulcer - a review. Digestion 1987;37(Suppl 2):31-41.

10. Gorbach SL. Bismuth therapy in gastrointestinal diseases. Gastroenterology 1990;99:863-75.

11. Lee SP. The mode of action of colloidal bismuth subcitrate. Scand J Gastroenterol Suppl 1991;185:1-6.

12. Goodwin CS, Marshall BJ, Blincow ED, Wilson DH, Blackbourn S, Phillips M. Prevention of nitroimidazole resistance in Campylobacter pylori by administration of colloidal bismuth subnitrate: clinical and in vitro studies. J Clin Pathol 1988;41:207-10.

13. Burette A, Glupczynski Y, DePrez C. Evaluation of various multi-drug eradication regimens for Helicobacter pylori. Eur J Gastroenterol Hepatol 1992;4:817-23.

14. DeCross AJ, Marshall BJ, McCallum RW, Hoffman SR, Barrett LJ, Guerrant RL. Metronidazole susceptibility testing for Helicobacter pylori: comparison of disk, broth, and agar dilution methods and their clinical relevance. J Clin Microbiol 1993;31:1971-4.

15. Chiba N, Rao BV, Rademaker JW, Hunt RH. Meta-analysis of the efficacy of antibiotic therapy in eradicating Helicobacter pylori. Am J Gastroenterol 1992;87:1716-27.

16. NIH Consensus Conference. Helicobacter pylori in peptic ulcer disease. NIH Consensus Development Panel on Helicobacter pylori in Peptic Ulcer Disease. JAMA 1994;272:65-9.

17. Chiba N, Hunt RH. Drug therapy of H pylori infection: a metaanalysis. In: Bianchi Porro G, Scarpignato C. Clinical Pharmacology and Therapy of H pylori Infection. (Lomax P, Scarpignato C, Vesell ES, eds. Progress in Basic and Clinical Pharmacology, vol 11). Basel: Karger Publishers, 1999:227-68.

18. Penston JG, McColl KEL. Eradication of Helicobacter pylori: an objective assessment of current therapies. Br J Clin Pharmacol 1997;43:223-43.

19. Tytgat GNJ. Review article: treatments that impact favourably upon the eradication of Helicobacter pylori and ulcer recurrence. Aliment Pharmacol Ther 1994;8:359-68.

20. Chiba N, Hunt RH. Bismuth, metronidazole and tetracycline $(\mathrm{BMT})+/$ - acid suppression in $\mathrm{H}$ pylori eradication: a meta-analysis. Gut 1996;39(Suppl 2):A36. (Abst 4A:27)

21. de Boer W, Driessen W, Jansz A, Tytgat G. Effect of acid suppression on efficacy of treatment for Helicobacter pylori infection. Lancet 1995;345:817-20.

22. de Boer WA, van Etten RJ, Schade RW, et al. One-day intensified lansoprazole-quadruple therapy for cure of Helicobacter pylori infection. Aliment Pharmacol Ther 1997;11:109-12.

23. de Boer WA, van Etten RJXM. Weekend lansoprazole quadruple therapy for Helicobacter pylori infection. Gut 1997;41(Suppl 1):A97. (Abst 09/355)

24. de Boer WA, van Etten RJXM, Schade RWB, Ouwehand ME, Schneeberger PM, Tytgat GNJ. 4-day lansoprazole quadruple therapy: a highly effective cure for Helicobacter pylori infection. Am J Gastroenterol 1996;91:1778-82.

25. de Boer WA, Driessen WM, Tytgat GN. Only four days of quadruple therapy can effectively cure Helicobacter pylori infection. Aliment Pharmacol Ther 1995;9:633-8.

26. de Boer WA, van Etten RJ, Schneeberger PM. Four-day lansoprazolequadruple therapy in the routine treatment of Helicobacter pylori infection. Neth J Med 1998;52:10-5.

27. de Boer WA, Driessen WM, Jansz AR, Tytgat GN. Quadruple therapy compared with dual therapy for eradication of Helicobacter pylori in ulcer patients: results of a randomized prospective single-centre study. Eur J Gastroenterol Hepatol 1995;7:1189-94.

28. de Boer WA, van Etten RJ, Lai JY, Schneeberger PM, van de Wouw BA, Driessen WM. Effectiveness of quadruple therapy using lansoprazole, instead of omeprazole, in curing Helicobacter pylori infection. Helicobacter 1996;1:145-50.

29. Graham DY, Hoffman J, el Zimaity HM, Graham DP, Osato M. Twice a day quadruple therapy (bismuth subsalicylate, tetracycline, metronidazole plus lansoprazole) for treatment of Helicobacter pylori infection. Aliment Pharmacol Ther 1997;11:935-8.
30. McColm AA, McLaren A, Klinkert G, et al. Ranitidine bismuth citrate: a novel anti-ulcer agent with different physicochemical characteristics and improved biological activity to a bismuth citrate-ranitidine admixture. Aliment Pharmacol Ther 1996;10:241-50.

31. Stables R, Campbell CJ, Clayton NM, et al. Gastric anti-secretory, mucosal protective, anti-pepsin and anti-Helicobacter properties of ranitidine bismuth citrate. Aliment Pharmacol Ther 1993;7:237-46.

32. McLaren A, Donnelly C, McDowell S, Williamson R. The role of ranitidine bismuth citrate in significantly reducing the emergence of Helicobacter pylori strains resistant to antibiotics. Helicobacter 1997;2:21-6.

33. Midolo PD, Lambert JR, Kerr TG. Ranitidine bismuth citrate can overcome in vitro antibiotic resistance in Helicobacter pylori. Gut 1997;41(Suppl 1):A12. (Abst 01/31)

34. McLaren A, McDowell SR, Bagshaw JA, McColm AA. The synergistic interaction between GR122311X and clarithromycin against Helicobacter. Am J Gastroenterol 1994;89:1382. (Abst 388)

35. Osato MS, Graham DY. Overcoming clarithromycin resistance with the combination of clarithromycin and ranitidine bismuth citrate. Gut 1997;41(Suppl 1):A104-5. (Abst 09/386)

36. Osato MS, Graham DY. Ranitidine bismuth citrate enhances clarithromycin activity against clinical isolates of $\mathrm{H}$ pylori. Gastroenterology 1997;112:A1057. (Abst)

37. López-Brea M, Domingo D, Sánchez I, Alarcón T. Synergism study of ranitidine bismuth citrate and metronidazole against metronidazole resistant H. pylori clinical isolates. Gastroenterology 1997;112:A201. (Abst)

38. van der Wouden EJ, Thijs JC, Van Zwet AA, Kooy A, Kleibeuker JH. One-week triple therapy with ranitidine bismuth citrate, clarithromycin and metronidazole versus two-week dual therapy with ranitidine bismuth citrate and clarithromycin for Helicobacter pylori infection: a randomized, clinical trial. Am J Gastroenterol 1998;93:1228-31.

39. Perschy TB, McSorley DJ, Sorrells SC, Webb DD. Ranitidine bismuth citrate in combination with clarithromycin is effective against $H$. pylori strains with susceptible or intermediate clarithromycin sensitivity. Gastroenterology 1997;112:A257. (Abst)

40. Mégraud F, Pichavant R, Palegry D, French PC, Roberts PM, Williamson R. Ranitidine bismuth citrate (RBC) co-prescribed with clarithromycin is more effective in the eradication of Helicobacter pylori than omeprazole with clarithromycin. Gut 1997;41(Suppl 1):A92. (Abst 09/337)

41. Osato M, Graham DY, Vakil N, et al. Development of clarithromycin resistance is 2.7 times less likely with ranitidine bismuth citrate than with omeprazole. Gastroenterol 1998;114:A249. (Abst G1022)

42. Graham DY, Hoffman J, Anderson SY, Qureshi W, Osato MS, El-Zimaity HM. Ranitidine bismuth citrate, tetracycline, clarithromycin twice-a-day triple therapy for clarithromycin susceptible Helicobacter pylori infection. Aliment Pharmacol Ther 1999;13:169-72.

43. de Boer WA, Haeck PWE, Otten MH, Mulder CJJ. Optimal treatment of Helicobacter pylori with ranitidine bismuth citrate (RBC): a randomized comparison between two 7-day triple therapies and a 14day dual therapy. Am J Gastroenterol 1998;93:1101-7.

44. Kung NN, Sung JJ, Yuen NW, et al. One-week ranitidine bismuth citrate versus colloidal bismuth subcitrate-based anti-Helicobacter triple therapy: a prospective randomized controlled trial. Am J Gastroenterol 1999;94:721-4.

45. Knigge K, Kelly C, Peterson WL, Fennerty MB. Eradication of Helicobacter pylori infection after ranitidine bismuth citrate, metronidazole and tetracycline for 7 or 10 days. Aliment Pharmacol Ther 1999;13:323-6.

46. Lind T, Mégraud F, Unge P, et al. The MACH2 study: role of omeprazole in eradication of Helicobacter pylori with 1-week triple therapies. Gastroenterology 1999;116:248-53.

47. Bardhan KD, Morton D, Perry MJ, et al. Ranitidine bismuth citrate with clarithromycin given alone or with metronidazole for 7 days effectively eradicates H. pylori. Gastroenterology 1998;114:A66. (Abst G0266)

48. van der Wouden EJ, Thijs JC, Zwet AA, Kooy A, Kleibeuker JH. The influence of metronidazole resistance on the efficacy of ranitidine bismuth citrate triple therapy regimens for Helicobacter pylori infection. Aliment Pharmacol Ther 1999;13:297-302. 


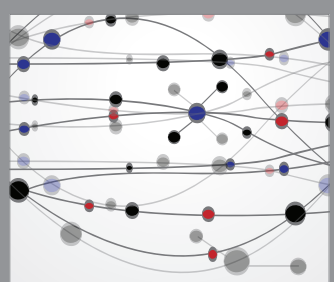

The Scientific World Journal
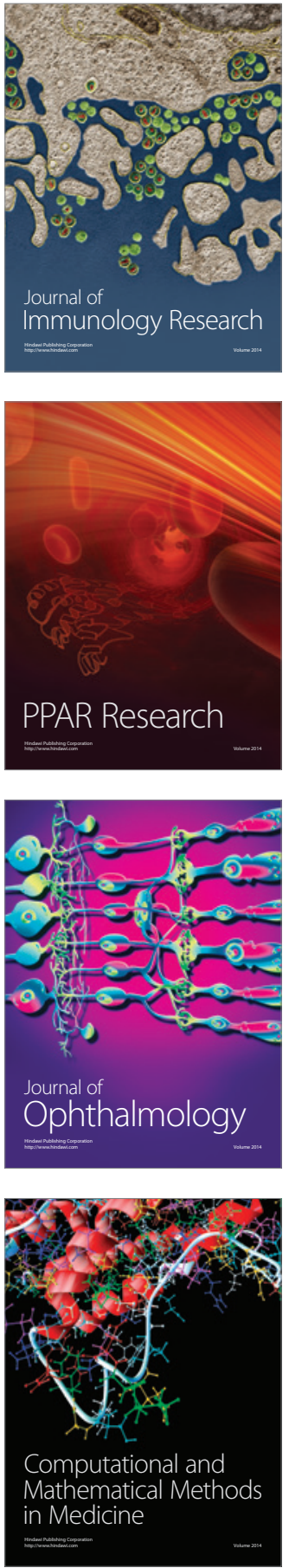

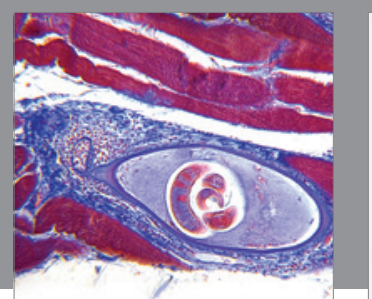

Gastroenterology Research and Practice

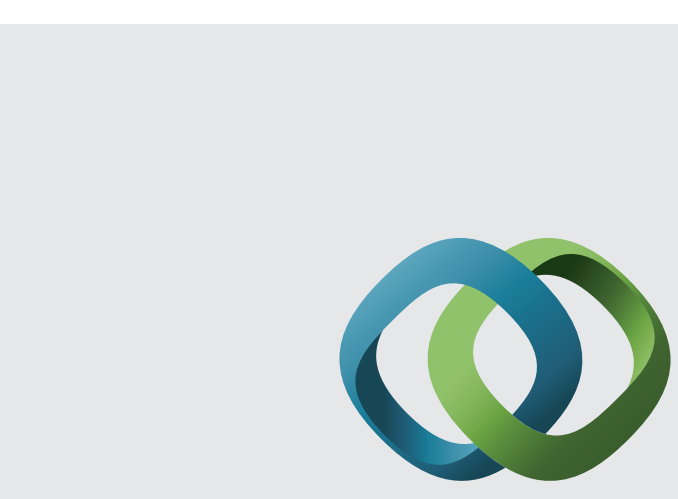

\section{Hindawi}

Submit your manuscripts at

http://www.hindawi.com
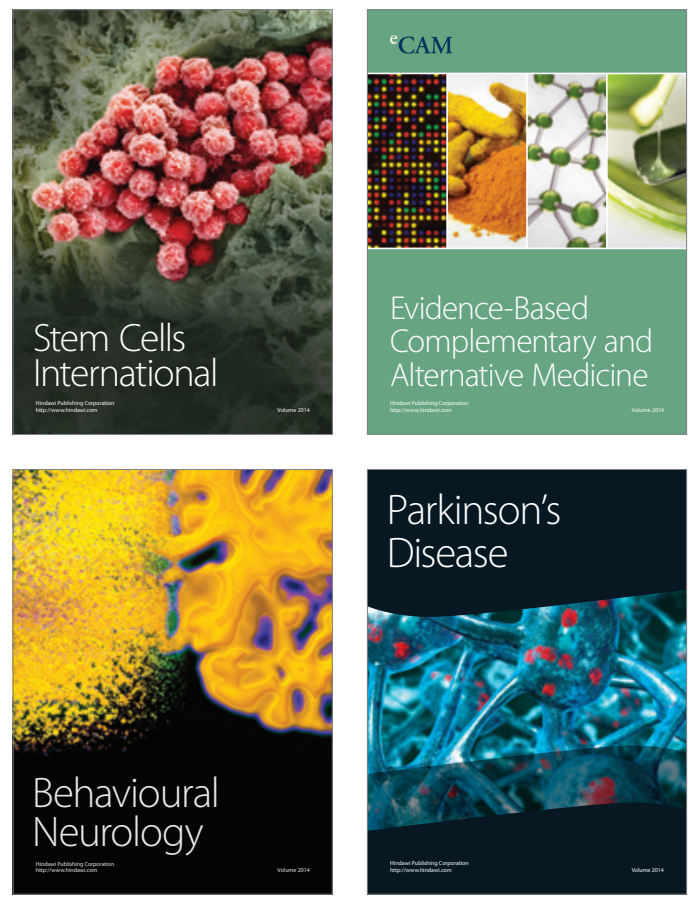
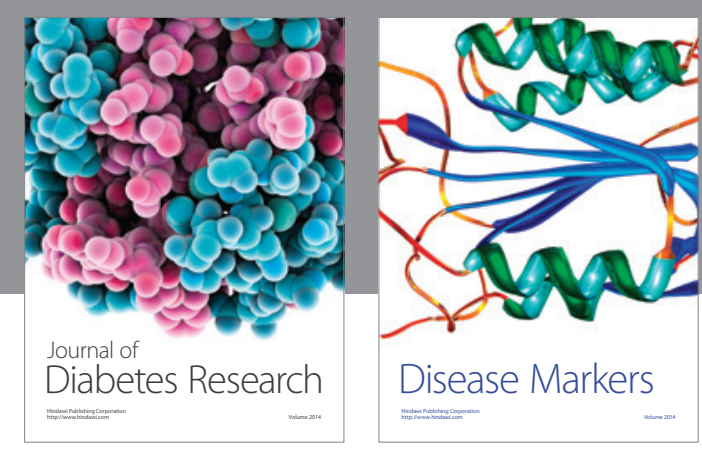

Disease Markers
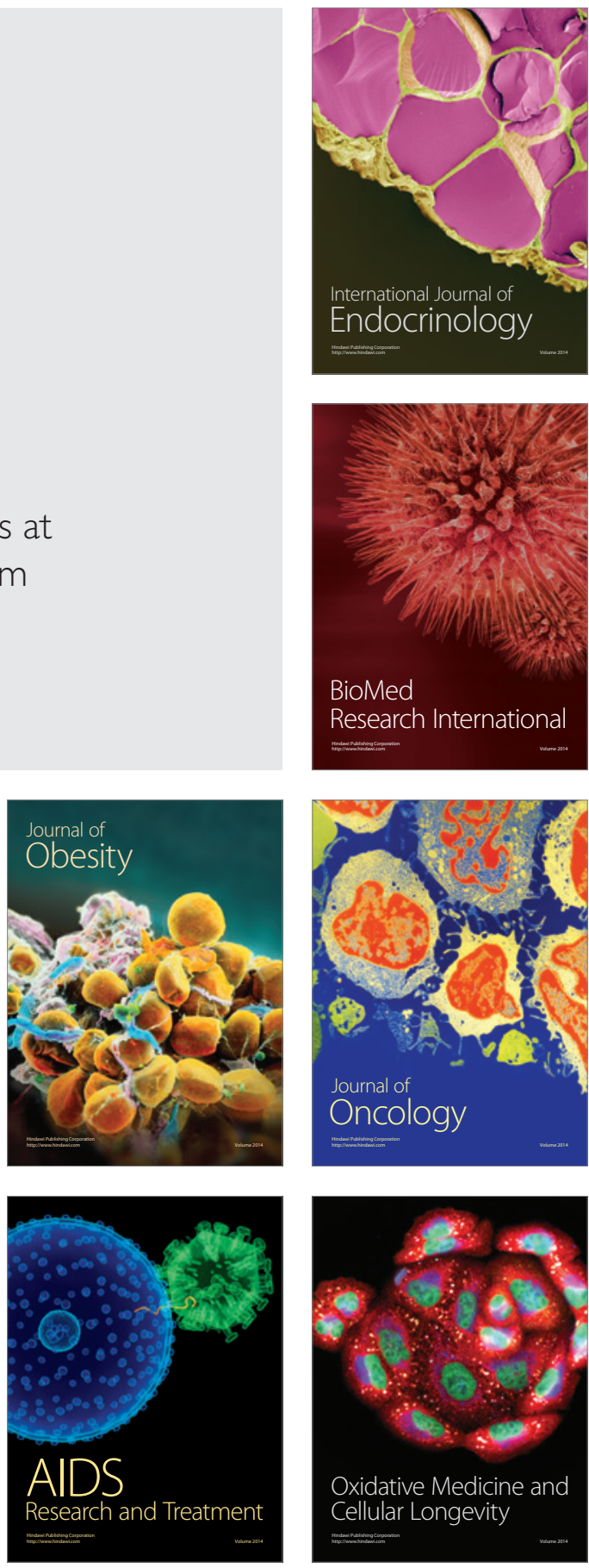